\title{
Microstructure Evolution of Commercial-Purity Titanium during Cryorolling
}

\author{
G. S. D'yakonov ${ }^{a}$, S. V. Zherebtsov ${ }^{b}$, M. V. Klimova ${ }^{b}$, and G. A. Salishchev ${ }^{b}$ \\ ${ }^{a}$ Institute of Physics of Advanced Materials, Ufa State Aviation Technical University, \\ ul. K. Marksa 12, Ufa, 450000 Russia \\ ${ }^{b}$ Laboratory of Bulk Nanostructured Materials, Belgorod State National Research University, \\ ul. Pobedy 85, Belgorod, 308015 Russia \\ e-mail:dgr84@mail.ru
}

Received February 7, 2014; in final form March 12, 2014

\begin{abstract}
Electron backscatter diffraction and transmission electron microscopy have been used to analyze the microstructural evolution of titanium during rolling at a cryogenic temperature $\left(T=-196^{\circ} \mathrm{C}\right)$. It has been found that intensive twinning at the cryogenic deformation temperature accelerates the kinetics of microstructure refinement. The quantitative analysis of microstructure evolution in titanium upon cryorolling has shown that structure evolution is mainly related to mechanical twinning in the initial stages. A substructure is developed and deformation-induced high-angle boundaries are formed in the range of mean and high degrees of deformation. It was established that rolling to the total degree of deformation $\varepsilon=93 \%(e=2.6)$ at $T=-196^{\circ} \mathrm{C}$ leads to the formation of a titanium microstructure with a grain/subgrains size approximately $80 \mathrm{~nm}$. The contribution of mechanical twinning and dislocation gliding in structural transformations in titanium with increasing degree of deformation during cryorolling is discussed.
\end{abstract}

Keywords: titanium, cryorolling, twinning, dislocation gliding, microstructure refinement, EBSD

DOI: $10.1134 /$ S0031918X14090038

\section{INTRODUCTION}

The lower-temperature deformation treatment of metals to high degrees of deformation may be accompanied by a decrease in the grain size and a significant increase in strength properties of the metals [1]. A number of techniques of so-called severe plastic deformation (SPD) have been developed that ensure that greater degrees of deformation can be accumulated in a sample without fracturing it. For example, equal channel angular pressing (ECAP) [2], high-pressure torsion [3], multi-axis forging [4], twist extrusion [5], and others. The main approach used in the SPD techniques is based on achieving large accumulated degrees of deformation and developing dynamic structural recrystallization [1]. Meanwhile, substantial microstructure refinement in some metals can be achieved without the involvement of labor-intensive SPD techniques, if one considers the peculiarities of acting deformation mechanisms and microstructure evolution. In titanium, both mechanical twinning and dislocation gliding are active during plastic deformation $[6,7]$. In this case, twinning may be considered to be a process that intensifies the refinement of the microstructure, since it is characterized by the formation of new high-angle boundaries. This feature of microstructure evolution in titanium may advantageously be used to produce ultrafine grain or nano- structures [8-10] at relatively small degrees of deformation, in this case using the standard techniques of metal pressure treatment. For example, a microstructure with a grain size of $100-200 \mathrm{~nm}$ was attained during plane-strain rolling at room temperature to a true strain $\varepsilon \approx 2.6[9]$.

The effect of dislocation gliding and mechanical twinning in titanium is known to depend on several factors, such as the degree [11], the temperature $[12,13]$ and rate of deformation, the amount of impurities $[6,7]$, and the particularities of the texture $[6,14]$. Depending on the combination of these factors, the deformation can occur via two mechanisms, or one of the deformation mechanisms can be suppressed for some reason or other. In this paper, based on the results of scanning and transmission electron microscopy, we have analyzed the development of dislocation gliding and mechanical twinning upon cryorolling . In particular, the results of the quantitative analysis of the development of mechanical twinning and the kinetics of the increment of low- and highangle boundaries in titanium at cryogenic deformation are new.

In our previous work, we showed that microstructure evolution in titanium upon room rolling is first associated with twinning and, second, with the formation of large-deformation-induced high-angle bound- 
Table 1. Chemical composition of titanium VT1-0 (wt \%) in the initial state

\begin{tabular}{c|c|c|c|c|c|c|c}
\hline $\mathrm{Ti}$ & $\mathrm{Al}$ & $\mathrm{Si}$ & $\mathrm{Fe}$ & $\mathrm{C}$ & $\mathrm{O}$ & $\mathrm{N}$ & $\mathrm{H}$ \\
\hline Balance & 0.01 & 0.1 & 0.18 & 0.07 & 0.12 & 0.04 & 0.01 \\
\hline
\end{tabular}

aries [9]. Lowering the deformation temperature [15] leads to an increase in the critical shear stress (CSS) of the dislocation gliding with virtually no impact on the twinning stress. In this regard, the intensification of twinning should be expected, as well as the redistribution of the contributions of mechanical twinning and dislocation gliding in microstructure evolution. In turn, this must affect the kinetics of the structural evolution of titanium upon deformation. As a result, in the present work, special attention was paid to the kinetics of mechanical twinning development and understanding of the twinning effect on the microstructure evolution in titanium during rolling at $T=$ $-196^{\circ} \mathrm{C}$. The results on the kinetics of the increment of low- and high-angle boundaries are presented. The results indicate the activity of mechanical twinning and dislocation gliding in titanium with increasing degree of deformation at cryogenic temperature.

\section{EXPERIMENTAL}

The material used in the present investigation is a 4-mm-thick sheet of titanium VT1-0, the chemical composition of which is shown in Table 1 .

In the initial state, a microstructure consisted from equiaxed recrystallized grains with an average size of $15 \mu \mathrm{m}$. Samples $4 \times 10 \times 30 \mathrm{~mm}^{3}$ in size, which were cut from the sheet, were placed in a container made of titanium to ensure isothermal conditions during rolling. Immediately before rolling, the container with a sample inside it was immersed in liquid nitrogen $\left(-196^{\circ} \mathrm{C}\right)$ and kept there until its complete cooling. During the rolling, the temperature of a sample did not increase by more than $20^{\circ} \mathrm{C}$. After each pass, the container was cooled in liquid nitrogen. Microstructural examination were carried out in the rolling plane at the half-thickness of the sample by optical (Olympus GX71), scanning (Quanta 600Feg), and transmission electron microscopy (JEOL JEM-2100FX).

The dislocation density in a local area of the foil was determined by counting the individual dislocations within grains/subgrains according the standard procedure described in [16], using at least six arbitrarily selected TEM images for each sample. The dislocation density was calculated using the formula $\rho=2 N / L t$, where $N$ is the number of dislocation intersections with random lines in the studied area $S$, $L$ is the total length of random lines, and $t$ is the thickness of the foil. The foil thickness $t$ was determined by the method of extinction contours using the formula $t=n \xi_{g}$ [16], where $n$ is the number of extinction contours and $\xi_{\mathrm{g}}$ is the extinction length.
EBSD maps obtained using the Quanta 600FEG scanning electron microscope was processed by TSL $\mathrm{OIM}^{\mathrm{TM}}$ software. Gray and black lines in the EBSD maps indicate low-angle boundaries (LABs) and highangle boundaries (HABs), respectively. Due to the restrictions of the EBSD method, we excluded misorientations of less than $2^{\circ}$ from the data analysis. The density of high- and low-angle boundaries was calculated as the ratio of their length to the area of EBSD maps, which gives the dimension $\mu^{-1}$. The EBSD method was used to analyze twin boundaries. The fraction of twin boundaries among the total amount of high-angle boundaries was determined using the misorientation; i.e., all of the boundaries in which misorientations did not deviate from the ideal twin boundary by more than $\pm \Delta \theta=15^{\circ} / \sqrt{\Sigma}$, were attributed to a specific system of twinning (Brandon criterion [17]).

\section{RESULTS}

Figure 1 shows a titanium microstructure in the initial state and after cryorolling to $10,30,60$, and $93 \%$.

The initial microstructure consists of equiaxed recrystallized grains with an average size of $15 \mu \mathrm{m}$ (Fig. 1a). After rolling to $10 \%$, the microstructure changes significantly due to the formation of a number of twins that separate the grain and sometimes intersect with one another (Fig 1b). Almost all grains are involved in the process of twinning; some of them exhibit secondary twinning. Increasing the degree of deformation to $30 \%$ leads to a significant increase in the number of twins in the structure (Fig. 1c). In most crystallites, the number of twins is so great that almost the entire volume of the grain is filled with twins. At the same time, there are grains where twinning has been less active. After rolling to $60 \%$, a heterogeneous structure is formed that consists of retained twins, fine crystallites, and coarser elongated grains (Fig. 1d). Fine grains with sizes of $0.2-1 \mu \mathrm{m}$ are close to equiaxed in shape and have high-angle misorientations where the grains sometimes contain individual subboundaries. Coarse grains $\geq 2 \mu \mathrm{m}$ in size are separated by more extended and branched subboundaries (Fig. 1d). As the degree of deformation increases to $93 \%$, a microstructure presenting a grain-subgrain mixture is formed.

Transmission electron microscopy after rolling to $10 \%$ shows groups of twins of different widths (Fig 2a). The average width of twins was $1.2 \mu \mathrm{m}$ (Table 2). 

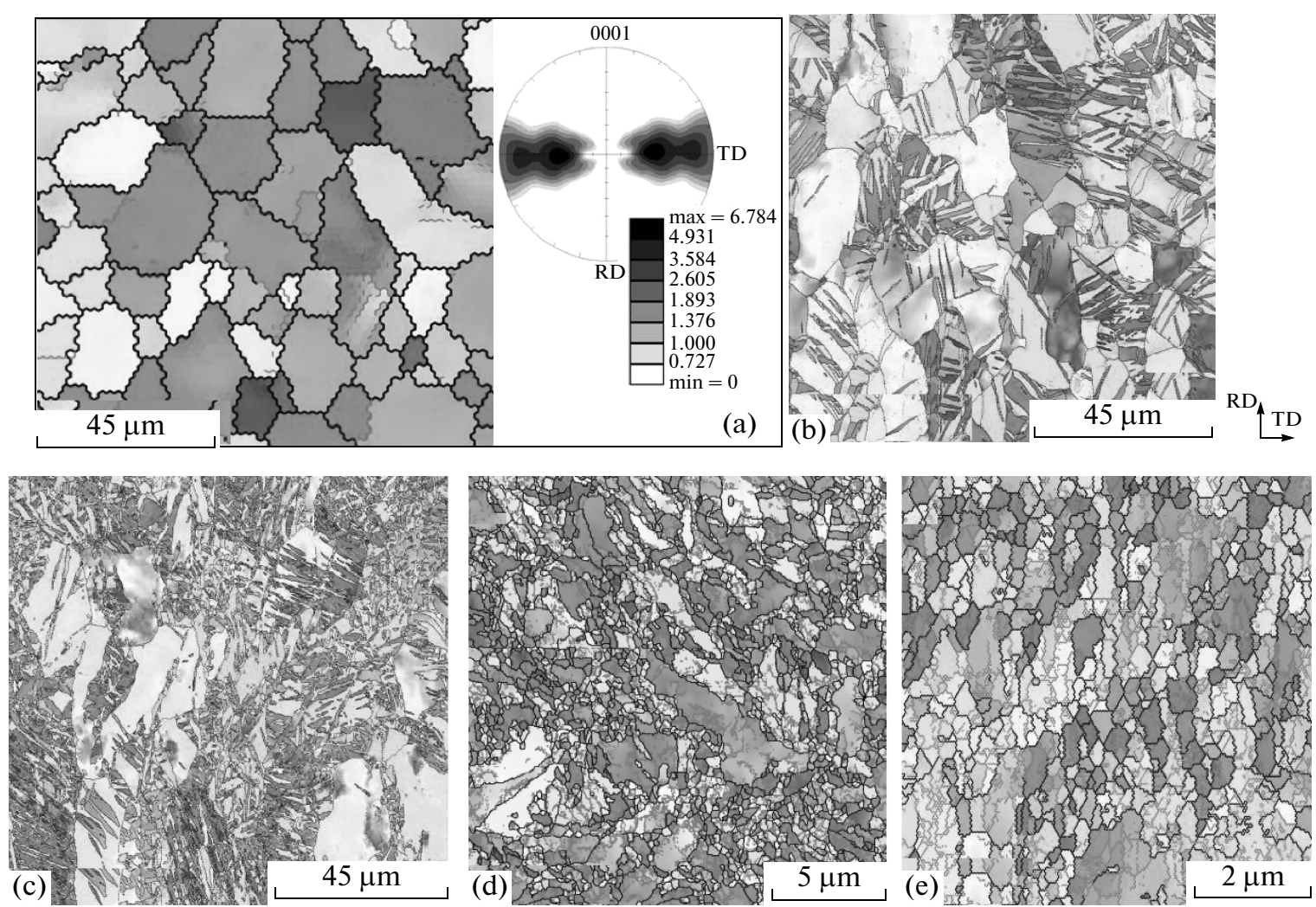

Fig. 1. EBSD maps of titanium microstructure: (a) in the initial state; and after cryorolling in the rolling plane to the following degree: (b) 10; (c) 30; (d) 60; and (e) 93\%.

The dislocation density in different structural areas varies strongly: from individual dislocations to dense dislocation clusters. The number of twins increases (Fig. 2b) and their average width decreases to $0.7 \mu \mathrm{m}$ with increasing the degree of deformation to $30 \%$. The intersection of twins and secondary twinning (Fig. 1b) breaks the structure into fragments that vary in size from $0.4 \mathrm{~nm}$. There is a sharp increase in the dislocation density at a degree of deformation of $40 \%$ in the structure.

In the space between twins, a substructure is formed with rather wide and fuzzy dislocation boundaries (Fig 2c). Twins along the length are divided into sections with different contrasts. Rolling titanium to $60 \%$ at the cryogenic temperature results in the formation of subgrains through various mechanisms, e.g.,

Table 2. Width of twins and the distance between them depending on the degree of the cryogenic rolling of titanium

\begin{tabular}{c|c|c}
\hline $\begin{array}{c}\text { Degree } \\
\text { of deformation, \% }\end{array}$ & $\begin{array}{c}\text { Average twin } \\
\text { width, } \mu \mathrm{m}\end{array}$ & $\begin{array}{c}\text { Average distance } \\
\text { between twins, } \mu \mathrm{m}\end{array}$ \\
\hline 10 & 1.2 & 3.5 \\
20 & 1 & 3 \\
30 & 0.7 & 2.8 \\
\hline
\end{tabular}

dividing twins by transverse boundaries (Fig. 2d) and through the formation of sub-boundaries and dislocation walls. As a result, a nonuniform structure comprised of grains and subgrains with different sizes of $50-500 \mathrm{~nm}$, as well as fragments of twins (Fig. 2e), is formed. The overall results of the EBSD (Fig. 1d) and TEM (Fig. 2e) studies do not contradict or complement each other. An increase in the degree of deformation to $93 \%$ improves the structural uniformity and substantially refines the microstructure, so the average grain/subgrain size is $80 \mathrm{~nm}$ (Fig. 2e). The presence of equiaxed dislocation-free grains/subgrains with thin straight boundaries in the structure (Fig 2) should be noted, which seems unusual for low-temperature deformation and is more characteristic of the structure resulted from recovery and recrystallization processes.

Titanium structural changes during cryorolling were analyzed using variations in the density of highand low-angle boundaries (EBSD data in Fig. 3a) and the average grain size (EBSD and TEM data in Fig. 3b). It is clear from these data that an increase in the density of low-angle boundaries upon cryrolling 1 occurs first slowly (up to $\sim 10 \%$ of deformation), then increases almost linearly, reaching $\sim 6 \mu \mathrm{m}^{-1}$ at the maximum degree of deformation. The change in the density of high -angle boundaries has three characteristic stages. At the first stage, at a degree of deformations of $\leq 20 \%$, mechanical twinning is a dominant 

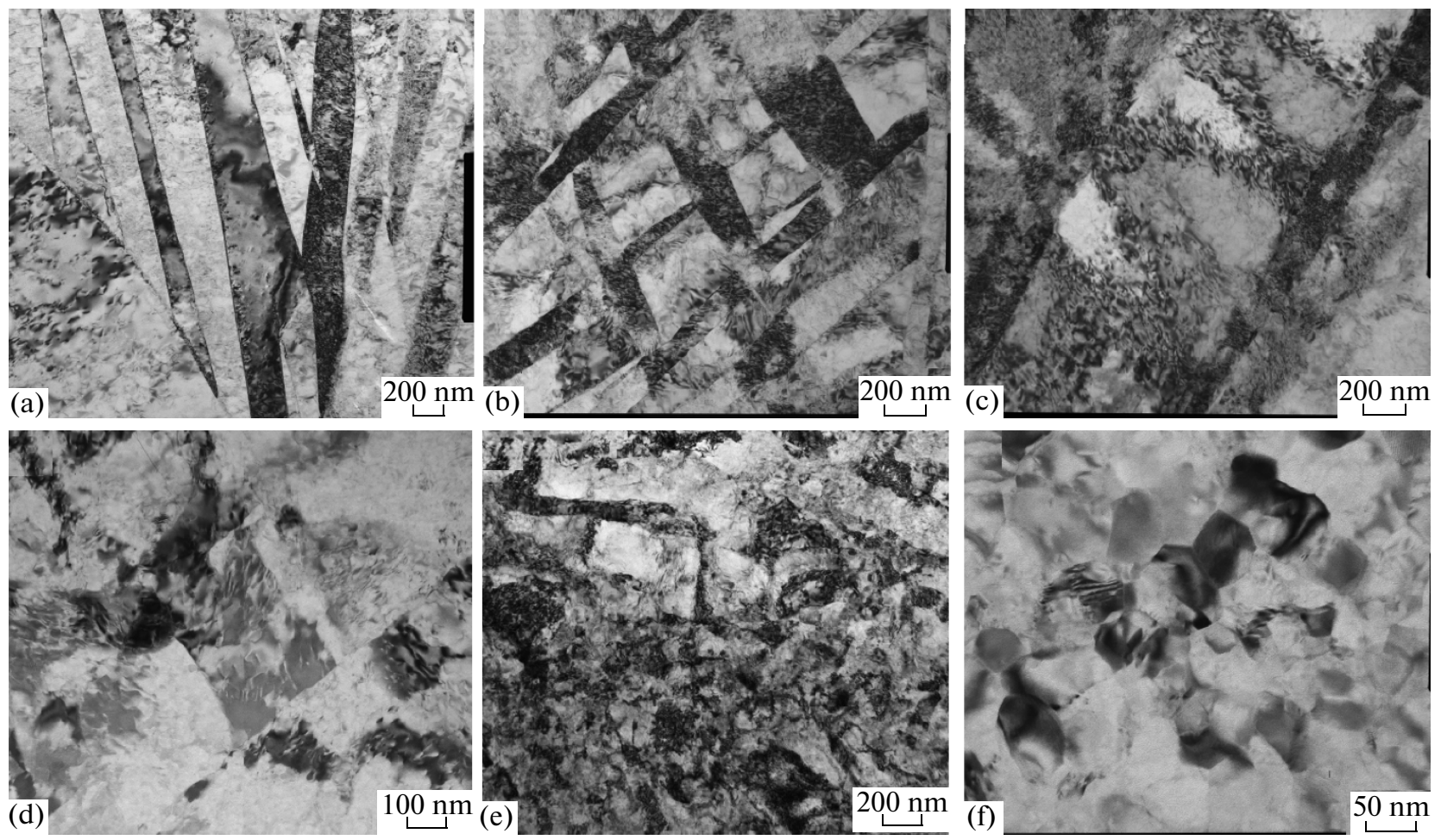

Fig. 2. Microstructure of titanium after cryogenic deformation to: (a) 10; (b) 30; (c) 40; (d), (e) 60; and (f) 93\% (TEM; in the rolling plane).

(a)

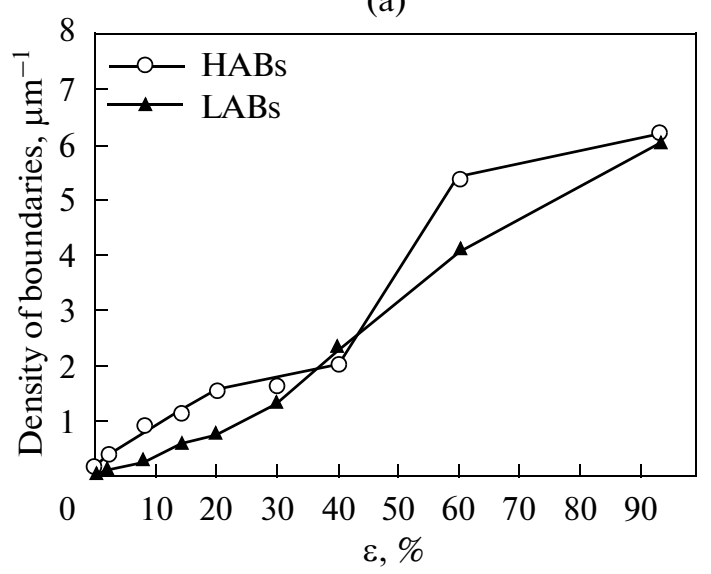

(b)

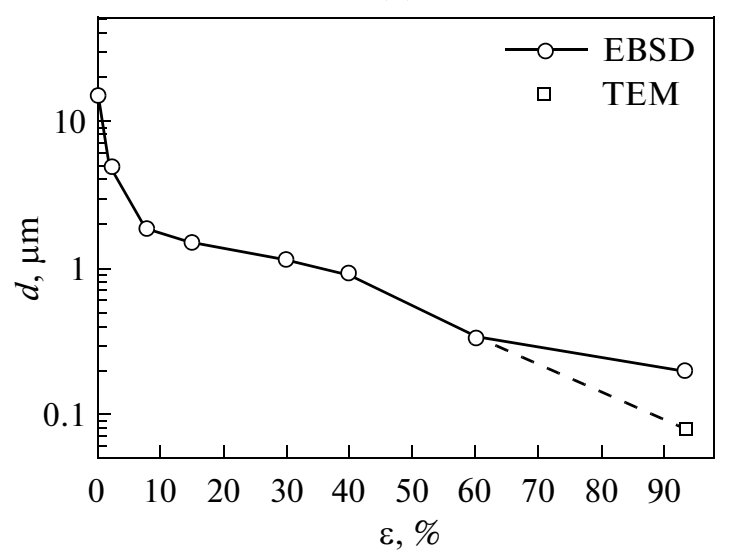

Fig. 3. (a) Density of low- and high-angle boundaries and (b) the average grain size vs. the degree of deformation upon cryorolling of titanium.

process, which results in the increment of special high-angle boundaries (Fig. 3a) and intensive refinement of the microstructure (Fig. 3b).

At the second stage, in the range $20 \% \leq \varepsilon \leq 40 \%$, an increment of HABs is markedly reduced due to the suppression of twinning during structural refinement [18]. For this reason, the average grain size is slowly refined as compared with the first stage (Fig. 3b). The third stage, at $\varepsilon>40 \%$, is characterized by the formation of deformation-induced high-angle boundaries, which resulted in the intensive growth of their density and a decrease in grain sizes.

It should be noted that TEM data indicate smaller sizes of grains/subgrains in the microstructure after $93 \%$ cryorolling compared with EBSD data (Figs. 2f, 3b). Since TEM provides a greater precision in the evaluation of the structure with such small grains (although in localized regions), one can assume that the true density of HABs is somewhat higher after $93 \%$ rolling than it can be seen from Fig. 3a. Importantly, the den- 


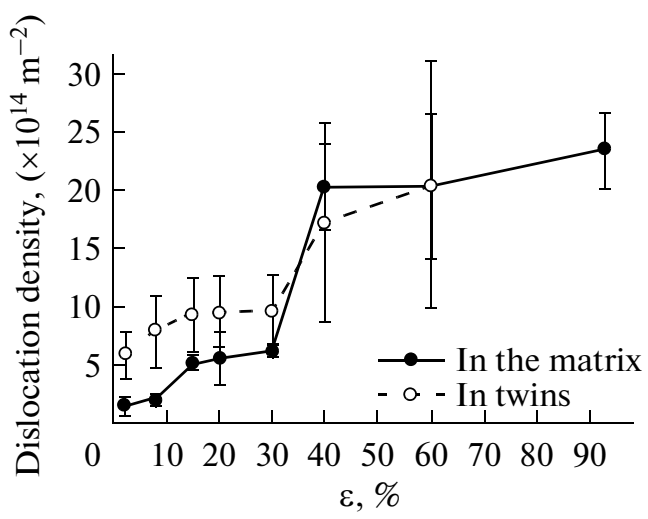

Fig. 4. Change in the dislocation density in the matrix and twins upon cryorolling of titanium.

sity of HABs (Fig. 3a) over the entire investigated range of degree of deformations was higher than that of LABs. The opposite case was observed upon roomtemperature rolling [9]. Accordingly, the results of this study indicate that the decrease in the deformation temperature effect the contribution of acting deformation mechanisms that control structural transformations in titanium.

The stagelike behavior of the evolution of a titanium structure upon cryorolling is also supported by the dependence of the dislocation density estimated in the matrix and in twins on the degree of deformation (Fig. 4). There are three characteristic regions in both curves, similar as in the HAB density curve (Fig. 3). Up to $30 \%$ of deformation, in the first stage, there is a slight increase in the dislocation density both within twins and in the matrix. Obviously, this is due to the fact that, at lower temperatures, twinning occurs more actively than dislocation gliding; therefore, deformation mostly implemented through twinning. The second stage is in the range of $30-40 \%$ of the degree of deformations after twinning has completed and is characterized by intensive growth in the dislocation density in the material volume. The extended third stage starts after $40 \%$ deformation. It is characterized by a slowly varying dislocation density. Note that, in the initial stages of deformation, the dislocation density in twins is higher than that in the matrix due to the conversion of mobile dislocations into fixed dislocations in the twinned regions (Basinsky effect [19]) and the need to form new mobile dislocations. However, after $\varepsilon=30 \%$ (i.e., after twinning), the dislocation densities become the same in twins and the matrix.

According to the EBSD data, a large amount of HABs with misorientations that correspond to the perfect twinning one has been formed upon the cryorolling of titanium with the most active formation of compressive twins $\{11 \overline{2} 2\}\langle 11 \overline{2} \overline{3}\rangle$ (misorientation between the matrix and a twin of $64^{\circ}$, Fig. 5a).

The fraction of tensile twins $\{10 \overline{1} 2\}\langle 10 \overline{1} \overline{1}\rangle\left(84^{\circ}\right)$ also increases by $20 \%$ of the deformation. It follows from Fig. $5 b$ that the fraction of twin misorientations gradually decreases with an increase in the degree of deformation which is first associated with the starvation of twinning up to $\varepsilon=20 \%$ and, second, is associated with the change in the orientation of twin boundaries due to the interaction with lattice dislocations [20] and their escape from the Brandon interval. It is worth noting that a decrease in the deformation temperature to the cryogenic temperature increases the length and intensity of twinning compared with roomtemperature deformation [9]. As can be seen from Fig. 5b, there are twin misorientations, even after $60 \%$ deformation in the volume of the material. The results shown in Table 2 indicate that the width of twins and the distance between twins decrease with increasing the degree of cryogenic rolling, at least to $30 \%$. In this case, the formation of new thinner twins occurs, rather than decreasing the amount of already formed twins. (a)

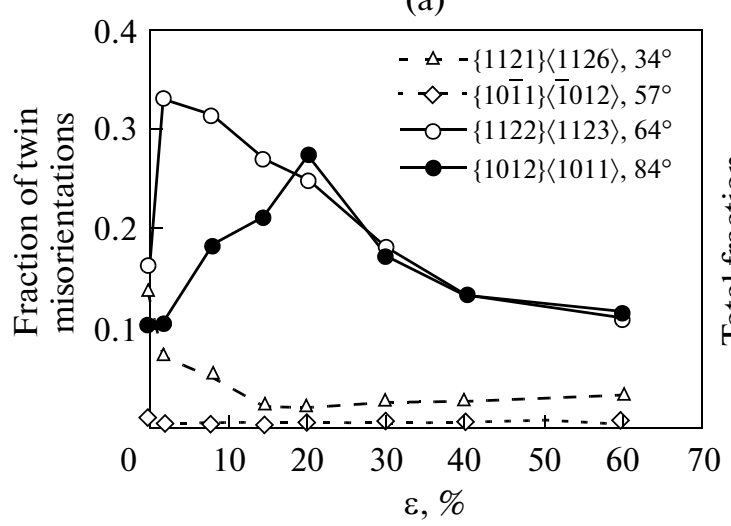

(b)

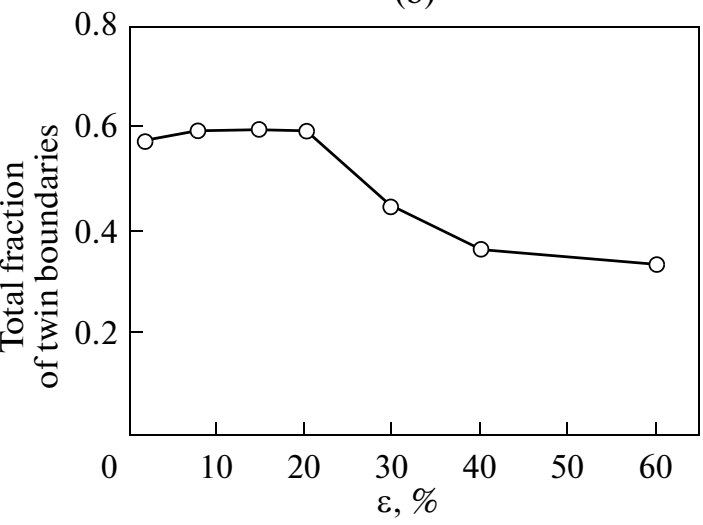

Fig. 5. (a) Acting systems of twinning and (b) the proportion of twin boundaries in titanium with increasing degree of cryogenic deformation. 


\section{DISCUSSION}

The results of this study allowed us to estimate the effect of temperature on the acting deformation mechanisms and to demonstrate the possibility of significant microstructure refinement in titanium by rolling under cryogenic deformation. It was shown that such mechanism of plastic deformation as mechanical twinning and the influence of the deformation temperature on it play an important role in the formation of a fine grain structure. Increasing the CSS of the dislocation gliding at lower temperature deformation changes the kinetics of the development of gliding and twinning during the plastic deformation of titanium. At low deformation temperatures, the difference between the values of CSS for dislocation gliding and mechanical twinning decreases as shown in [15]. In connection with this, the contribution of mechanical twinning in the evolution of the microstructure at a cryogenic deformation temperature will increase and be higher than, e.g., at room temperature.

As follows from the obtained results, the active development of twinning at $e \leq 10 \%$ leads to growth in HABs, while the density of LABs remains at almost the same level, which confirms the reduced activity of dislocation gliding in the initial stage of plastic deformation (Fig. 3a). Moreover, plastic deformation at a cryogenic temperature results in a prolongation of the stage of twinning. For example, according to $[8,11]$, at room temperature, twinning disappears with up to $40 \%$ deformation. In [9], the fraction of twin boundaries after room-temperature rolling to 20 and $60 \%$ was 2.5 and 1.8 times lower, respectively, than those after cryogenic deformation.

The formation of new high-angle boundaries due to twinning leads to a decrease in the average grain size during rolling (Fig. 3). It is known that the stress needed for the emergence of a twin increases faster than that required to activate gliding with a decrease in the grain size [15, 21-23]. Thus, twinning is suppressed at a some critical grain size. At room-temperature deformation, according to [23], the critical grain size in titanium is nearly $0.7 \mu \mathrm{m}$, while according to [18], it is $0.6 \mu \mathrm{m}$. The increased CSS of dislocation gliding at cryorolling (compared to room-temperature deformation) shifts the critical grain size at which twinning is still possible toward smaller values and prolongs the extent of the twinning stage. This fact is supported by the results of our study.

As follows from the microstructural studies (Figs. 1, 2), the active development of twinning at cryogenic rolling effectively refines the microstructure already in early stages of deformation. The cryogenic temperature of deformation leads not only to an increase in the volume of twinning, but somehow changes the character of twinning development. Multiple intersections between twins are typical of cryorolling (Figs. 1c, 2b). These intersections result in the formation of almost equiaxed fragments with highangle misorientations (Fig. 2b). Similar active inter- section of twins is not typical for room-temperature rolling [9]. Secondary twinning makes an additional contribution to the refinement of the titanium microstructure upon cryorolling.

The activity of deformation mechanisms that operate upon cryorolling is reflected in the stagelike behavior of the density of HABs and dislocation density (Figs. 3a, 4). An increase in the CSS of dislocation gliding at cryogenic temperature of deformation causes the redistribution of the contribution of dislocation gliding and mechanical twinning in the total deformation. The activation of twinning provides HABs growth (Fig 3a) and suppresses dislocation gliding (Fig 4) at the first stage.

In the second stage, at $20 \% \leq \varepsilon \leq 40 \%$, the basic mechanism of deformation changes from twinning to dislocation gliding due to the structure refinement (Fig. 3a). The fact that twinning is over is reflected in the less intense, than in the first stage, increment in HABs, while the activation of dislocation gliding is seen in the increasing dislocation density at $30 \% \leq e \leq$ $40 \%$ (Fig. 4). In turn, the increasing role of dislocation gliding stimulates the development of a substructure (Fig. 3a).

The other increment in HABs is observed at $\varepsilon \geq$ $40 \%$ and is due to the formation of deformationinduced high-angle boundaries. We can assume that the uneasiness of deformation and increased local stresses activate multiple gliding, which results in the formation of branched low-angle boundaries and increases their misorientation in the recently refined grains (Fig.1d). The dislocation density at the third stage $(\varepsilon \geq 40 \%)$ did not change significantly, which could be due to the development of recovery and recrystallization processes. This is also indicated by the presence in the structure of equiaxed dislocationfree grains/subgrains with thin straight boundaries (Fig. 2e). The formation of these grains/subgrains during warm deformation is usually attributed to the development of continuous dynamic recrystallization, but in the case of low temperatures it seems rather unusual because of the lack of sufficient thermal activation of the process. At the same time, in the literature [24-26], local recrystallization and grain boundary migration are possible at a low temperature under high stress. One of the conditions that stimulate the dynamic recrystallization at low temperatures in highly deformed materials is a high concentration of vacancies $[27,28]$.

\section{CONCLUSIONS}

In this paper, we analyzed the structural evolution of titanium during cryorolling at $T=-196^{\circ} \mathrm{C}$ to a degree of deformation of $\varepsilon=93 \%$. The following conclusions were drawn:

(1) Plastic deformation of titanium at cryogenic temperature activates twinning and prolongs the twinning stage, as compared to room-temperature defor- 
mation. The development of twinning in the initial stages of cryogenic deformation provides the substantial microstructure refinement.

(2) The change in the density of high-angle boundaries with increasing the degree of cryogenic deformation indicates the presence of three characteristic stages. The first stage is characterized by the rapid development of twinning, due to which a substantial increment in HABs is observed. In the second stage, twinning disappears and the role of dislocation gliding increases. The third stage is characterized by the increment in deformation-induced HABs due to the active dislocation gliding.

(3) The quantitative analysis of structural changes upon the cryorolling of titanium indicates a change in the activity of acting deformation mechanisms. At the first stage of increment of HABs, the controlling deformation mechanism is mechanical twinning. At the second stage, the role of dislocation gliding increases, while twinning gradually disappears because of the decrease in the average grain size. At the third stage, the controlling deformation mechanism is dislocation gliding.

\section{REFERENCES}

1. R. Z. Valiev and I. V. Aleksandrov, Bulk Nanostructured Metallic Materials: Production, Structure and Properties (Akademkniga, Moscow, 2007) [in Russian].

2. R. Z. Valiev and T. G. Langdon, "Principles of equalchannel angular pressing as a processing tool for grain refinement," Prog. Mater. Sci. 51, 881-981 (2006).

3. A. P. Zhilyaev and T. G. Langdon, "Using high-pressure torsion for metal processing: Fundamentals and applications,” Prog. Mater. Sci. 53, 893-979 (2008).

4. G. A. Salishchev, S. Yu. Mironov, and S. V. Zherebtsov, "Mechanisms of submicrocrystalline structure formation in titanium and two-phase titanium alloy during warm severe processing," Rev. Adv. Mater. Sci., No. 11, 152-158 (2006).

5. Y. Beygelzimer, V. Varyukhin, S. Synkov, and D. Orlov, "Useful properties of twist extrusion," Mater. Sci. Eng., A 503, 14-17 (2009).

6. H. Conrad, "Effect of interstitial solutes on the strength and ductility of titanium," Prog. Mater. Sci. 26, 123403 (1981).

7. B. A. Kolachev, Physical Metallurgy of Titanium (Metallurgiya, Moscow, 1976) [in Russian].

8. Y. B. Chun, S. H. Yu, S. L. Semiatin, and S. K. Hwang, "Effect of deformation twinning on microstructure and texture evolution during cold rolling of CP-titanium," Mater. Sci. Eng., A 398, 209-219 (2005).

9. S. V. Zherebtsov, G. S. Dyakonov, A. A. Salem, S. P. Malysheva, G. A. Salishchev, and S. L. Semiatin, "Evolution of grain and subgrain structure during cold rolling of commercial-purity titanium," Mater. Sci. Eng., A 528, 3474-3479 (2011).

10. V. A. Moskalenko, A. R. Smirnov, and A. V. Moskalenko, "Cryomechanically obtained nanocrystalline titanium: Microstructure and mechanical properties," Low Temp. Phys. 35, 905-907 (2009).
11. E. V. Nesterova and V. V. Rybin, "Mechanical twinning and fragmentation of commercial titanium on the stage of developed plastic deformation," Fiz. Met. Metalloved. 59, 395-406 (1985).

12. U. Zwicker, Titan und Titanlegierungen (Springer-Verlag, Berlin, 1977; Metallurgiya, Moscow,1979).

13. M. G. Glavicic, A. A. Salem, and S. L. Semiatin, "X-ray line-broadening analysis of deformation mechanisms during rolling of commercial-purity titanium," Acta Mater. 52, 647-655 (2004).

14. A. A. Pochettino, N. Gannio, C. Vial Edwards, and R. Penelle, "Texture and pyramidal slip in $\mathrm{Ti}, \mathrm{Zr}$ and their alloys," Scr. Metall. Mater. 27, 1859-1863 (1992).

15. M. A. Meyers, O. Vöhringer, and V. A. Lubarda, "The onset of twinning in metals: A constitutive description," Acta. Mater. 49, 4025-4039 (2001).

16. P. Hirsh, A. Howie, R. Nicholson, D. Pashley, and M. Whelan, Electron Microscopy of Thin Crystals (Butterworths, Lonson, 1977; Mir, Moscow, 1968).

17. D. G. Brandon, "The structure of high-angle grain boundaries," Acta Metall. 14, 1479-1484 (1966).

18. S. V. Zherebtsov, G. S. Dyakonov, A. A. Salem, V. I. Sokolenko, G. A. Salishchev, and S. L. Semiatin, "Formation of nanostructures in commercial-purity titanium via cryorolling," Acta Mater. 61, 1167-1178 (2013).

19. Z. S. Basinski, M. S. Szczerba, M. Niewczas, J. D. Embury, and S. J. Basinski, "The transformation of slip dislocations during twinning of copper-aluminum alloy crystals," Rev. Metall. 94, 1037-1043 (1997).

20. G. Salishchev, S. Mironov, S. Zherebtsov, and A. Belyakov, "Changes in misorientations of grain boundaries in titanium during deformation," Mater. Characterization 61, 732-739 (2010).

21. N. Stanford, U. Carlson, and M. R. Barnett, "Deformation twinning and the Hall-Petch relation in commercial purity Ti,” Metall. Mater. Trans. A 39, 934944 (2008).

22. M. R. Barnett, Z. Keshavarz, A. G. Beer, and D. Atwell, "Influence of grain size on the compressive deformation of wrought $\mathrm{Mg}-3 \mathrm{Al}-1 \mathrm{Zn}$," Acta Mater. 52, 5093-5103 (2004).

23. Qian Yu, Zhi-Wei Shan, Ju Li, X. Huang, Lin Xiao, Jun Sun, and Evan Ma, "Strong crystal size effect on deformation twinning," Nature 463, 335-338 (2010).

24. D. A. Molodov, A. V. Ivanov, and G. Gottstein, "Low angle tilt boundary migration coupled to shear deformation," Acta Mater. 55, 1843-1848 (2007).

25. M. Winning and A. D. Rollett, "Transition between low and high angle grain boundaries," Acta Mater. 53, 2901-2907 (2005).

26. J. W. Cahn and Y. Mishin, "Recrystallization initiated by low-temperature grain boundary motion coupled to stress,” Int. J. Mater. Res. 100, 510-515 (2009).

27. M. A. Shtremel', Strength of Alloys. Ch. II. Deformation (MISIS, Moscow, 1997) [in Russian].

28. F. Humphreys and M. Hatherly, Recrystallization and related annealing phenomena, 2 nd ed. (Elsevier, Oxford, 2004). 